\title{
Spirometric Changes during Pregnancy in Cystic Fibrosis Patients
}

\author{
Clay Wu ${ }^{1 *}$, Gloria Wu², Lynn Fukushima1, Adupa P. Rao'1, Ahmet Baydur'1 \\ ${ }^{1}$ Division of Pulmonary, Critical Care and Sleep Medicine, University of Southern California, Los Angeles, California, USA \\ ${ }^{2}$ Department of Internal Medicine, University of Southern California, Los Angeles, California, USA \\ Email: *clay.wu@med.usc.edu
}

How to cite this paper: $\mathrm{Wu}, \mathrm{C}$., $\mathrm{Wu}, \mathrm{G}$., Fukushima, L., Rao, A.P. and Baydur, A. (2021) Spirometric Changes during Pregnancy in Cystic Fibrosis Patients. Open Journal of Respiratory Diseases, 11, 19-25. https://doi.org/10.4236/ojrd.2021.111002

Received: December 22, 2020

Accepted: February 23, 2021

Published: February 26, 2021

Copyright (c) 2021 by author(s) and Scientific Research Publishing Inc. This work is licensed under the Creative Commons Attribution International License (CC BY 4.0).

http://creativecommons.org/licenses/by/4.0/

(c) (i) Open Access

\begin{abstract}
Rationale: Survival and longevity in patients with cystic fibrosis (CF) have improved with new treatments, so that pregnancy can be safely undertaken despite physiologic limitations. Dyspnea still develops in the latter stages of pregnancy. To explain this symptom, we evaluated the effect of pregnancy on lung function before and after delivery. Methods: Records of 23 pregnant patients with CF were retrospectively reviewed for data analysis. Spirometry was recorded prior to pregnancy, at first and third trimesters, and every three months following delivery up to one year. Comparisons between time points were adjusted for age and pre-gestational BMI by analysis of variance (ANOVA). Results: Complete clinical and spirometric data were available for eleven of these patients (13 pregnancies total), obtained between 2009 and 2017. FEV1 and FVC declined significantly from baseline to third trimester (by $8.1 \%, p<0.043$ and $9.3 \%, p<0.013$, respectively). No statistically significant differences amongst spirometric values were observed, however, when adjusted for BMI and age over the entire time course. FEV1 and FVC recovered to baseline six months and one year following delivery, respectively. Conclusions: The changes in FEV1 and FVC occur as a result of increases in intravascular blood volume and lung water during the third trimester. At the same time, FEV1/FVC increases as there is reversal of bronchiolar constriction with elimination of extracellular fluid and lung water. Furthermore, restoration of end-expiratory lung volume post-partum counteracts reversal of air trapping with resolution of peribronchiolar edema, with FVC remaining unchanged. These changes would explain decrease in dyspnea following delivery in CF patients.
\end{abstract}

\section{Keywords}

Pulmonary Cystic Fibrosis, Pregnant Women, Spirometry, Respiratory Physiological Phenomena 


\section{Introduction}

With advancements in the treatment and management of cystic fibrosis (CF), patients with $\mathrm{CF}$ are increasingly surviving into adulthood. The estimated median age of survival for CF patients in the United States was found to be 30.8 years in 2018 [1]. As women with CF enter adulthood, they are encouraged to discuss fertility, family planning, and pregnancy with their clinicians. In general, pregnancy is likely a safe and viable option for women with CF though long-term consequences and risk factors for pregnancy are not well known in this patient population and need to be considered as part of pregnancy planning for CF patients. A few prior case series have suggested that patients with low FEV1 may be at increased risk for adverse events during pregnancy [2] [3]. Some studies also suggest that nutritional status and pancreatic insufficiency could also be risk factors for adverse outcome of pregnancy in CF patients. However, in more recent studies, including a prospective matched cohort comparing pregnant and non-pregnant CF patients, pregnancy was not found to have increased decline in lung function and worsening survival [4] [5] [6]. However, there is still a limited understanding of the impact of pregnancy on spirometry measurements in women with CF. In this study, we retrospectively reviewed the spirometry measurements of pregnant CF patients to evaluate and understand the effect of physiological changes during pregnancy on lung function.

\section{Methods}

\subsection{Setting}

We reviewed the medical records of all the CF patients who seek care at Keck Medical Center of USC between 2009 and 2017. We included all CF patients who underwent pregnancy at Keck Medical Center. The study was approved by the Institutional Review Board of the University of Southern California Health Sciences Center, HS-15-00892.

\subsection{Exclusion}

Exclusion criteria included patients without a diagnosis of CF, CF patients who did not become pregnant, patients who did not have complete spirometric data for analysis, patients who were lost to follow up. There were $23 \mathrm{CF}$ patients identified, with 12 excluded due to the criteria above.

\subsection{Variables Assessed}

Of the 11 patients (13 pregnancies) included, information was collected on patient demographics, including age and BMI, and spirometry measurements, such as forced expiratory volume (FEV1) and forced vital capacity (FVC) were recorded at pre-pregnancy, first trimester, third trimester, and postpartum, every three months up until one year postpartum. 


\subsection{Statistical Analysis}

A retrospective analysis that adjusted for confounding factors such as age and pre-gestation BMI using two-factor analysis of variance (ANOVA) was conducted. Post-hoc analysis was then performed using paired two sample student t-test, using BMI of $22 \mathrm{~kg} / \mathrm{m}^{2}$ as the pre-defined cut-off, the recommended pre-gestational BMI by the CF Foundation.

\section{Results}

\subsection{Characteristics of the Cohort}

Of the eleven CF patients with thirteen pregnancies between 2009 to 2017, the mean age at the onset of pregnancy was 29.5 years with a range of 24 to 35 years. The patients had a mean pre-pregnancy BMI of $23.0 \mathrm{~kg} / \mathrm{m}^{2}$ and a range of 17.5 to $29.4 \mathrm{~kg} / \mathrm{m}^{2}$. None of the patients had a history of smoking. Nine of the eleven patients had pancreatic insufficiency. Two patients had CF related diabetes prior to pregnancy. Five of the thirteen pregnancies were achieved with Caesarean section. There were no maternal or neonatal complications. The mean pre-pregnancy FEV1 was $2.49 \mathrm{~L} \pm 0.81 \mathrm{SEM}$ which correlates with $80.9 \%$ predicted and mean pre-pregnancy FVC was $3.22 \mathrm{~L} \pm 0.94$ SEM which correlates with $83.2 \%$ predicted. Five of the eleven patients had normal pre-pregnancy spirometry measurements where FVC and FEV1 were greater than $80 \%$ predicted (Table 1).

\subsection{Findings}

There was a significant decline in FEV1 and FVC from pre-pregnancy to the third trimester of pregnancy of $8.1 \%$, $(\mathrm{p}<0.043)$ and $9.3 \%,(\mathrm{p}<0.013)$, respectively.

Table 1. Characteristics of the eleven CF patients who underwent thirteen pregnancies. Values are all pre-pregnancy.

\begin{tabular}{cccccccc}
\hline $\begin{array}{c}\text { Age } \\
\text { (years) }\end{array}$ & $\begin{array}{c}\text { BMI } \\
\left(\mathrm{kg} / \mathrm{m}^{2}\right)\end{array}$ & Diabetes & $\begin{array}{c}\text { Pancreatic } \\
\text { Insufficiency }\end{array}$ & $\begin{array}{c}\text { Smoking } \\
\text { History }\end{array}$ & $\begin{array}{c}\text { Type of } \\
\text { delivery }\end{array}$ & $\begin{array}{c}\text { Delivery } \\
\text { complications }\end{array}$ & $\begin{array}{c}\text { Neonatal } \\
\text { complications }\end{array}$ \\
\hline 35.1 & 22.46 & No & Yes & None & C section & None & None \\
32.3 & 21.65 & No & Yes & None & C section & None & None \\
29.6 & 24.03 & No & Yes & None & Vaginal & None & None \\
34.3 & 18.20 & No & Yes & None & Vaginal & None & None \\
31.2 & 20.48 & No & Yes & None & C section & None & None \\
26.2 & 21.62 & No & No & None & Vaginal & None & None \\
25.9 & 25.31 & No & Yes & None & C section & None & None \\
31.5 & 20.09 & Yes & Yes & None & Vaginal & None & None \\
26.4 & 29.44 & No & No & None & Vaginal & None & None \\
24.5 & 25.59 & No & No & None & Vaginal & None & None \\
24.0 & 17.50 & No & Yes & None & C section & None & None \\
30.0 & 28.31 & No & Yes & None & Vaginal & None & None \\
32.6 & 24.39 & Yes & Yes & None & Vaginal & None & None \\
\hline
\end{tabular}




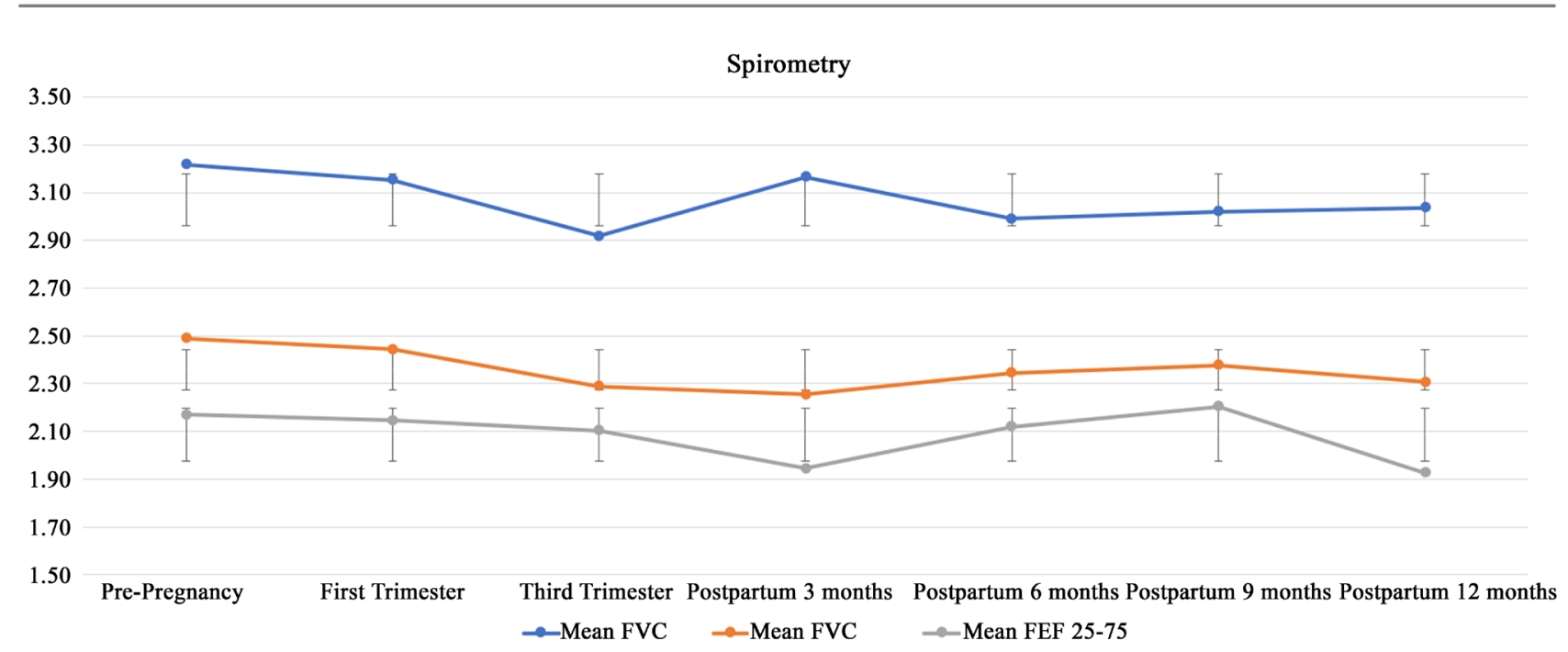

Figure 1. Mean spirometry values for the thirteen CF pregnancies from pre-pregnancy until 12 months postpartum.

When adjusted for BMI and age, there were no statistically significant differences in the decline of FEV1 and FVC from pre-pregnancy to third trimester. The decrease in FEV1 during pregnancy recovered at six months postpartum while the FVC returned to baseline values by one-year post-partum. There was no association between pre-pregnancy FEV1 or FVC values and decline in these values during pregnancy (Figure 1). During the third trimester, the FEF 25 - 75 decreased by $10.1 \%(p=0.038)$, then over the next 6 months returned to baseline before declining again by $12.7 \%(\mathrm{p}=0.039)$ one year post-partum.

There were no individuals who developed gestational diabetes over the course of their pregnancy.

\section{Discussion}

In this retrospective analysis of CF patients undergoing pregnancy, we have shown that pregnancy is generally well-tolerated despite leading to a temporary decline in lung function in the third trimester. We found a significant decline FEV1 and FVC during the third trimester that later recovers one year postpartum. These findings are similar to a prior study which also found that both FEV1 and FVC were significantly decreased at the time of delivery [3]. During normal respiratory physiology of pregnancy, serial spirometry measurements of healthy pregnant patients have found that FEV1 and FVC remain unchanged throughout the pregnancy [7] [8]. A reduction in FRC has been well-documented in pregnancy. A decrease in both expiratory reserve volume (ERV) and residual volume (RV) develop as a result of decreased chest wall elasticity and an increase in pulmonary blood volume due to progesterone-induced vasodilation [9] [10]. However, this is typically compensated for by chest wall changes that occur, such as an increase in the subcostal angle and the overall chest wall circumference which help preserve lung function and capacity. The change in spirometric volumes due to elevation of the diaphragm typically resolves within days of delivery [7] [8]. During normal pregnancy, there is airway narrowing due to mucos- 
al edema, hyperemia, increased plasma leakage, and secretion of polysaccharides because of estrogen that peak in the third trimester [9] [10].

In addition, the increase intravascular plasma volume and decrease in plasma colloid osmotic pressure result in increased susceptibility to pulmonary edema and lung water accumulation [11] [12] [13] [14]. Our study shows that pregnant CF patients have a decline in lung function that is not seen in their healthy counterparts, and thus cannot be explained solely by diaphragmatic excursion or changes in the chest wall as the recovery in lung function took much longer. We suspect that the underlying respiratory disease due to CF leads to the decreased FEV1 and FVC during pregnancy observed in this study and that CF patients are more sensitive to the physiological changes during pregnancy. Abnormal mucociliary clearance is a hallmark of cystic fibrosis, and we propose that impaired clearance of these mucopolysaccharide secretions may lead to the prolonged decline in FEV1 and FVC seen. The decrease in FEF 25 - 75 (an index of small airway function) can also be explained by these changes, although as noted in Table 2 , its decline was more variable, indicating its greater sensitivity to changes in airway mechanics.

Table 2. Mean values for FEV1, FVC, FEF 25 - 75 during first and third trimester, and 3-month intervals postpartum up to a year.

\begin{tabular}{|c|c|c|c|c|}
\hline Spirometry & & FEV1 & FVC & FEF $25-75$ \\
\hline \multirow{3}{*}{ Baseline } & Mean & 3.22 & 2.49 & 2.17 \\
\hline & SD & 0.94 & 0.81 & 0.99 \\
\hline & Mean & 3.15 & 2.44 & 2.15 \\
\hline \multirow[t]{3}{*}{ First Trimester } & SD & 0.92 & 0.83 & 1.04 \\
\hline & $\mathrm{p}$-value & 0.261 & 0.376 & 0.824 \\
\hline & Mean & 2.92 & 2.29 & 2.10 \\
\hline \multirow[t]{3}{*}{ Third Trimester } & SD & 0.95 & 0.88 & 1.13 \\
\hline & $\mathrm{p}$-value & 0.013 & 0.043 & 0.648 \\
\hline & Mean & 3.17 & 2.26 & 1.95 \\
\hline \multirow{3}{*}{$\begin{array}{c}\text { Postpartum } 3 \\
\text { months }\end{array}$} & SD & 1.32 & 0.77 & 0.97 \\
\hline & $\mathrm{p}$-value & 0.013 & 0.008 & 0.038 \\
\hline & Mean & 2.99 & 2.35 & 2.12 \\
\hline \multirow[t]{3}{*}{$\begin{array}{c}\text { Postpartum } 6 \\
\text { months }\end{array}$} & SD & 0.98 & 0.90 & 1.17 \\
\hline & $\mathrm{p}$-value & 0.021 & 0.076 & 0.730 \\
\hline & Mean & 3.02 & 2.38 & 2.20 \\
\hline \multirow[t]{3}{*}{$\begin{array}{c}\text { Postpartum } 9 \\
\text { months }\end{array}$} & $\mathrm{SD}$ & 1.03 & 0.94 & 1.26 \\
\hline & $\mathrm{p}$-value & 0.012 & 0.109 & 0.832 \\
\hline & Mean & 3.04 & 2.31 & 1.92 \\
\hline \multirow{2}{*}{$\begin{array}{l}\text { Postpartum } 12 \\
\text { months }\end{array}$} & SD & 0.90 & 0.78 & 0.92 \\
\hline & $\mathrm{p}$-value & 0.051 & 0.009 & 0.039 \\
\hline
\end{tabular}


There is also a known close correlation between nutritional status and pulmonary function testing in CF patients [15]. In general, CF patients need to consume twice the number of daily calories in order to maintain their weight due to absorptive abnormalities associated with pancreatic insufficiency, particularly fat-soluble vitamin deficiencies. We also propose that over the course of the pregnancy a CF patient may become more nutritionally deficient due to the need to consume enough calories and nutrients for the fetus which may contribute to the decline in lung function seen in the third trimester. Subsequently, after delivery, as the patient begins to regenerate muscle strength, their lung function also recovers.

There were limitations to this study, mainly due to its retrospective nature and single center origin. Initially 23 subjects were chosen but data analysis was done only in 11 patients (completed data in 13 pregnancies). Clearly larger studies, preferably prospective in nature, would provide validation of our findings.

\section{Conclusion}

$\mathrm{CF}$ patients may experience a decline in FEV1 and FVC during pregnancy that may take several months and even up to a year postpartum to recover. As these changes in lung function are not seen during normal pregnancy, the temporary decline in lung function during pregnancy is likely due to decreased secretion clearance from the airways and nutritional deficiencies leading to muscle weakness to which CF patients are more susceptible.

\section{Acknowledgements}

We would like to acknowledge the pulmonary function laboratory technologists for their role in performing the spirometric tests.

\section{Conflicts of Interest}

The authors declare no conflicts of interest regarding the publication of this paper.

\section{References}

[1] Cystic Fibrosis Foundation (2019) Cystic Fibrosis Foundation Patient Registry. 2018 Annual Data Report. Bethesda.

[2] Edenborough, F.P., Stableforth, D., Webb, A.K., Mackenzie, W.E. and Smith, D.L. (1995) Outcome of Pregnancy in Women with Cystic Fibrosis. Thorax, 50, 170-174. https://doi.org/10.1136/thx.50.2.170

[3] Cohen, L.F., di Sant'Agnese, P.A. and Friedlander, J. (1980) Cystic Fibrosis and Pregnancy. A National Survey. The Lancet, 2, 842-844.

https://doi.org/10.1016/S0140-6736(80)90183-X

[4] Goss, C.H., Rubenfeld, G.D., Otto, K., et al. (2003) The Effect of Pregnancy on Survival in Women with Cystic Fibrosis. Chest, 124, 1460-1468.

https://doi.org/10.1378/chest.124.4.1460

[5] FitzSimmons, S.C., Fitzpatrick, S., Thompson, B., et al. (1996) A Longitudinal Study 
of the Effects of Pregnancy on 325 Women with Cystic Fibrosis. Pediatric Pulmonology. Supplement, 13, 99-101.

[6] McMullen, A.H., Pasta, D.J., Frederick, P.D., et al. (2006) Impact of Pregnancy on Women with Cystic Fibrosis. Chest, 129, 706-711. https://doi.org/10.1378/chest.129.3.706

[7] Bobrowski, R.A. (2010) Pulmonary Physiology in Pregnancy. Clinical Obstetrics and Gynecology, 53, 285-300. https://doi.org/10.1097/GRF.0b013e3181e04776

[8] Hegewald, M.J. and Crapo, R.O. (2011) Respiratory Physiology in Pregnancy. Clinics in Chest Medicine, 32, 1-13. https://doi.org/10.1016/j.ccm.2010.11.001

[9] Bernstein, I.M., Ziegler, W. and Badger, G.J. (2001) Plasma Volume Expansion in Early Pregnancy. Obstetrics \& Gynecology, 97, 669-672. https://doi.org/10.1016/S0029-7844(00)01222-9

[10] Lund, C.J. and Donovan, J.C. (1967) Blood Volume during Pregnancy. Significance of Plasma and Red Cell Volumes. American Journal of Obstetrics and Gynecology, 98, 394-403. https://doi.org/10.1016/0002-9378(67)90160-3

[11] Weinberger, S.E., Weiss, S.T., Cohen, W.R., Weiss, J.W. and Johnson, T.S. (1980) Pregnancy and the Lung. The American Review of Respiratory Disease, 121, 559-581. https://doi.org/10.1164/arrd.1980.121.3.559

[12] Elkus, R. and Popovich Jr., J. (1992) Respiratory Physiology in Pregnancy. Clinics in Chest Medicine, 13, 555-565.

[13] Cugell, D.W., Frank, N.R., Gaensler, E.A. and Badger, T.L. (1953) Pulmonary Function in Pregnancy. I. Serial Observations in Normal Women. American Review of Tuberculosis, 67, 568-597.

[14] Tan, E.K. and Tan, E.L. (2013) Alterations in Physiology and Anatomy during Pregnancy. Best Practice \& Research: Clinical Obstetrics \& Gynaecology, 27, 791-802. https://doi.org/10.1016/j.bpobgyn.2013.08.001

[15] Steinkamp, G. and Wiedemann, B. (2002) Relationship between Nutritional Status and Lung Function in Cystic Fibrosis: Cross Sectional and Longitudinal Analyses from the German CF Quality Assurance (CFQA) Project. Thorax, 57, 596-601. https://doi.org/10.1136/thorax.57.7.596 